\title{
Aditivos e sua influência no comportamento de secagem e resistência à tração de concretos refratários
}

\section{(Additives and their influence in the refractory castables drying and traction strength behavior)}

\author{
I. R. Oliveira, R. Salomão, V. C. Pandolfelli \\ Departamento de Engenharia de Materiais - DEMa, Universidade Federal de S. Carlos - UFSCar \\ Rod. Washington Luiz, km 235, C.P. 676, S. Carlos, SP 13565-905 \\ ivone@iris.ufscar.br,vicpando@power.ufscar.br
}

\begin{abstract}
Resumo
A evolução tecnológica de concretos refratários tem tornado mais difícil a etapa de secagem devido a redução da sua permeabilidade e conseqüente aumento da dificuldade para que o vapor de água migre do interior do corpo para a superfície. A hidratação do cimento de aluminato de cálcio também causa decréscimo da permeabilidade dos concretos. Tal processo é significativamente afetado pela presença de aditivos utilizados para a dispersão do concreto. Neste contexto, este trabalho teve como objetivo relacionar o tipo de aditivo utilizado no processamento de concretos refratários com seu comportamento de secagem e resistência à tração. Foi verificado que os aditivos não atuam somente na dispersão das partículas da matriz e ligante, mas o efeito da sua atuação pode influenciar no tipo de hidrato formado. O aditivo CS se mostrou um eficiente dispersante promovendo a redução no consumo de água. Isso acarretou na formação preferencial dos hidratos $\mathrm{C}_{3} \mathrm{AH}_{6}$ disponibilizando mais alumina para a formação de $\mathrm{AH}_{3}$. Essa fase apresenta alta capacidade de preencher vazios interparticulas contribuindo para aumentar a resistência à tração do material. Por outro lado, $\mathrm{o}$ aditivo AC desfavoreceu a formação desses tipos de hidratos uma vez que atua como retardador da hidratação do cimento por meio do consumo de íons cálcio. Também a presença de um maior teor de água nos concretos preparados com este aditivo pode explicar o aumento da porosidade e decréscimo da resistência à tração do concreto.
\end{abstract}

Palavras-chave: concretos refratários, aditivos, secagem, hidratos.

\begin{abstract}
The growing technology applied in the refractory castables production has become more difficult the drying process due the reduction of their permeability and the consequent increasing difficult of vapor migration from the inner region of the body to the surface. The hydration of calcium aluminate cement is also responsible for the castables permeability reduction. This process is significatively affected by the presence of additives used to disperse the castables. In this context, the objective of this work was to evaluate the influence of the different kind of additives on the drying behavior and traction strength of castables. It was verified that additives not only influence in the dispersion of matrix and binder particles but also in the type resulting hydrate. The additive CS favored the dispersion of castable and decreased water consumption resulting in the main formation of hydrates $C_{3} A H_{6}$ and $A_{3}$. The formation of $\mathrm{AH}_{3}$ is particularly favored by precipitation of $\mathrm{C}_{3} \mathrm{AH}_{6}$ due to alumina content available to its formation to be larger. This phase appears frequently as gel and due its high capacity to fill interparticle voids can be correlated to the traction strength development. On the other hand, in the presence of additive AC it was observed reduction in relation the formation these hydrates due his retarder effect which occurred by calcium ions consumption. Moreover, the presence of bigger water content contributed for increase of porosity and decrease of traction strength of castable.
\end{abstract}

Keywords: Refractory castables, drying, mechanical strength, hydration, cement.

\section{INTRODUÇÃO}

Os refratários são produtos fundamentais para uma vasta gama de indústrias. De modo geral, qualquer processo que envolva altas temperaturas depende do desempenho de refratários. A necessidade de melhorias de processos, aumento da eficiência e da produtividade resultam em contínuos investimentos para incrementar o nível de qualidade desses produtos. Dentre eles, os refratários monolíticos ou não prémoldados, como os concretos, têm se destacado em relação aos moldados convencionais devido a uma série de vantagens. Tais materiais não necessitam de conformação e queima prévia, apresentam facilidade de transporte, estocagem e aplicação, apresentam maior facilidade de manutenção, menor gasto de mão-de-obra e ausência de juntas [1].

Entretanto, a evolução tecnológica de refratários monolíticos tem resultado em materiais cada vez mais densos. Esse fato foi acompanhado por um aumento na dificuldade de secagem dos concretos, onde a aplicação de taxas de aquecimento inadequada pode levar a pressurização 
do vapor d'água dentro da estrutura e ocasionar a explosão do refratário; ou ainda elevar consideravelmente os gastos com energia e tempo de parada para manutenção de equipamentos. Isso ocorre devido a redução da permeabilidade desses materiais. Essa propriedade fluidodinâmica esta relacionada com a quantidade e distribuição da porosidade aberta existente na microestrutura, que atua como canal para o transporte de líquidos e gases pelo corpo. Dependendo da permeabilidade pode-se aumentar a dificuldade para que o vapor de água migre do interior do corpo para a superfície [2]

$\mathrm{O}$ cimento de aluminato de cálcio tem sido amplamente utilizado como ligante hidráulico em concretos refratários. Tais materiais exercem um papel fundamental no processamento dos refratários monolíticos, uma vez que atuam na formação das ligações que promovem resistência mecânica a verde nos produtos. Isso ocorre por meio do processo de hidratação das fases anidras do cimento resultando na formação de compostos hidratados responsáveis pela coesão do corpo. Embora o favorecimento desse processo resulte na elevação da resistência mecânica, a formação dessas fases acarreta em queda de permeabilidade do material dificultando a secagem.

$\mathrm{O}$ processo de hidratação pode ser significativamente modificado em função do tipo de cimento e da presença de diferentes tipos de aditivos orgânicos e inorgânicos. Tipos distintos de cimento podem diferir na composição mineralógica apresentando um maior teor da fase $\mathrm{C}_{12} \mathrm{~A}_{7}$, que por ser mais reativa favorece a precipitação de hidratos. Já a função principal dos aditivos em concretos é a dispersão das partículas da matriz visando a obtenção de altos valores de fluidez acarretando no decréscimo do consumo de água e em boa trabalhabilidade. Entretanto, os aditivos também influenciam a hidratação do cimento freqüentemente retardando ou acelerando as reações de precipitação [3-5]. Dessa forma, a secagem dos concretos refratários pode ser definida como a retirada da água livre e água quimicamente ligada durante a etapa de aquecimento inicial do material [6, 71. A água livre se refere àquela adicionada durante a mistura das matérias-primas e que permanece retida nos poros da estrutura após a etapa de cura. Já a quimicamente ligada está associada aos hidratos cristalinos e amorfos. As quantidades relativas de água livre e química dependem da quantidade de água adicionada à mistura do concreto, do teor e tipo de ligante e também da temperatura e tempo de cura.

Neste contexto, o presente trabalho teve como objetivo relacionar o tipo de aditivo utilizado no processamento de concretos refratários com seu comportamento de secagem e resistência à tração.

\section{MATERIAIS E MÉTODOS}

Os concretos refratários foram formulados segundo o modelo de empacotamento de partículas de Andreasen [8], com coeficiente (q) 0,21, por meio do software PSDesigner [9]. Aluminas eletrofundidas brancas com variação de tamanho de partículas na faixa de $4750-11 \mu \mathrm{m}$ foram usadas como agregado (69\%-p), enquanto a matriz constituiu-se das aluminas calcinadas A $17 \mathrm{NE}(22 \%-p)$ e CT3000SG (3\%-
Tabela I - Teores de aditivos e de água determinados para a preparação das diferentes composições dos concretos refratários.

[Table I - Additive and water content for the different refractory castables compositions.]

\begin{tabular}{cccc}
\hline Composição & $\begin{array}{c}\text { Tipo de } \\
\text { dispersante }\end{array}$ & $\begin{array}{c}\text { Teor de } \\
\text { dispersante } \\
(\%-p)\end{array}$ & $\begin{array}{c}\text { Teor de } \\
\text { água } \\
(\%-p)\end{array}$ \\
\hline \multirow{2}{*}{ CA14M } & Sem dispersante & - & 4,5 \\
ou Secar 71 & Ácido cítrico & 0,07 & 5,5 \\
& CD & 0,13 & 5,2 \\
& CS & 0,09 & 4,5 \\
\hline
\end{tabular}

p). Como agentes ligantes foram utilizados os cimentos de aluminato de cálcio CA14M da Almatis-US e Secar 71 da Kerneos-França (6\%-p). Como aditivos dispersantes foram avaliados os seguintes compostos: ácido cítrico anidro (Labsynth, $192 \mathrm{~g} / \mathrm{mol}$, 99,5\% pureza) e os polímeros da família do poliglicol, fornecidos pela Bayer (CD e CS). Os teores de aditivos e de água necessários para a preparação de cada composição foram previamente determinados [10] e são apresentados na Tabela I.

A mistura das matérias-primas, após pesagem das composições formuladas, foi realizada em um reômetro para concretos [11] com rotação constante de $44 \mathrm{rpm}$.

A adição do teor de água definido para cada tipo de composição foi realizada em etapas para garantir a efetiva mistura dos sistemas otimizando a fluidez [12, 13]. Após mistura a seco durante $60 \mathrm{~s}$, visando a quebra dos aglomerados e conseqüente homogeneização de seus componentes, adicionou-se $75 \%$ do total de água suficientes para a "virada do concreto", a qual pode ser definida como o momento no qual o concreto passa a se comportar como um meio contínuo. Ao alcançar o ponto de virada, o restante da água foi adicionado e a rotação foi mantida até a completa mistura do sistema.

Em seguida, os concretos foram moldados utilizandose moldes de PVC cilíndricos $(\mathrm{h}=\mathrm{d}=40 \mathrm{~mm})$ aos quais foi aplicada uma fina camada de desmoldante. Posteriormente, tais amostras foram curadas na temperatura de $50^{\circ} \mathrm{C}$ numa câmara climatizada Vötsch 2020, em ambiente saturado (umidade relativa $\cong 100 \%$ ) durante os períodos de $24,48,72$ e $168 \mathrm{~h}$.

Após os tempos definidos de cura, as amostras de concretos com as diferentes composições foram caracterizadas quanto à resistência à tração e perfil de secagem.

Os ensaios de resistência à tração por compressão diametral (ASTM C 496-90) foram realizados em amostras úmidas (imediatamente após a cura) ou secas (a $110{ }^{\circ} \mathrm{C}$ durante $3 \mathrm{~d}$ ) utilizando-se uma máquina de ensaios universal MTS 810 a uma taxa de aplicação de carga de $42 \mathrm{~N} / \mathrm{s}$. A tensão de ruptura foi calculada a partir da equação abaixo:

$$
\sigma_{\mathrm{R}}=2 \cdot\left(\frac{\mathrm{P}_{\max }}{\pi \cdot \mathrm{L} \cdot \mathrm{D}}\right)
$$


onde $\sigma_{R}$ é a tensão de ruptura (MPA), $\mathrm{P}_{\text {max }}$ é a força de ruptura (N), L é a altura (m), e D o diâmetro da amostra (m).

Neste tipo de ensaio, as amostras são submetidas a forças de compressão diametral exercidas pelo equipamento, gerando solicitações de tração no interior da amostra. A propagação da trinca ocorre na direção vertical visto que as tensões de tração principal atuam perpendicularmente a força aplicada. Este teste foi selecionado para avaliar a resistência à tração das amostras por proporcionar uma situação semelhante a que ocorre na etapa de secagem, quando os concretos refratários são submetidos à pressurização de vapor, isto é, a solicitação interna por tração.

Os ensaios de secagem foram realizados em amostras úmidas (imediatamente após a cura). Para composições de CA14M preparadas na presença do aditivo CS, os ensaios também foram realizados em amostras curadas durante $24 \mathrm{e}$ $168 \mathrm{~h}$ e secas a $110^{\circ} \mathrm{C}$ durante um dia. Concretos preparados com os aditivos ácido cítrico e CS na ausência de ligante curados durante $168 \mathrm{~h}$ a $50^{\circ} \mathrm{C}$ em ambiente saturado também foram submetidas a ensaios de secagem. $\mathrm{O}$ equipamento utilizado consiste de uma balança eletrônica acoplada a um forno elétrico. Foram coletadas simultaneamente a perda de massa da amostra e a temperatura do forno em função do tempo de ensaio. Em todos os ensaios também foram adicionadas ao forno amostras contendo um termopar para a coleta simultânea da temperatura na superfície da amostra. $\mathrm{O}$ aquecimento foi efetuado à $10^{\circ} \mathrm{C} / \mathrm{min}\left(30-800^{\circ} \mathrm{C}\right)$, com patamar de $20 \mathrm{~min}$ em $800{ }^{\circ} \mathrm{C}$. A perda de massa, avaliada pelo parâmetro $\mathrm{W}$ e sua derivada em relação ao tempo (taxa de secagem) são definidas respectivamente nas equações:

$$
\begin{aligned}
& W(\%)=100 \times\left(\frac{\left(M_{o}-M\right)}{\left(M_{o}-M_{f}\right)}\right) \\
& d W / d t(\% / m i n)=d / d t\left(\frac{\left(M_{o}-M\right)}{\left(M_{o}-M_{f}\right)}\right)
\end{aligned}
$$

onde $\mathrm{W}$ indica a perda de água que ocorre durante o aquecimento em relação a massa final de concreto seco, $\mathrm{M}$ é a massa instantânea medida no tempo $t_{i}, M_{0}$ a massa inicial, e $\mathrm{M}_{\mathrm{f}}$ a massa final.

Para amostras secas (a $110{ }^{\circ} \mathrm{C}$ durante 3 d) também foram realizados ensaios de porosidade aparente por meio do método de imersão de Archimedes, utilizando querosene como líquido de imersão (norma ASTM C830).

\section{RESULTADOS E DISCUSSÃO}

De acordo com estudo prévio [10], os aditivos avaliados neste trabalho mostram-se muito eficientes quanto a dispersão do concreto refratário, obtendo-se altos valores de fluidez livre (Tabela II). O aditivo CS resultou no maior valor de fluidez devido a alta eficiência que ele apresenta com relação a dispersão das partículas da matriz e principalmente
Tabela II - Fluidez livre (\%) dos concretos refratários preparados na presença de diferentes tipos de ligantes e aditivos.

[Table II - Free flowability (\%) of refractory castables prepared with different types of binders and additives.]

\begin{tabular}{ccc}
\hline & \multicolumn{2}{c}{ Ligantes } \\
\cline { 2 - 3 } Aditivos & CA14M & Secar 71 \\
\hline Ácido cítrico & 121 & 125 \\
CD & 100 & 112 \\
CS & 126 & 126 \\
\hline
\end{tabular}

do ligante. Esse elevado estado de dispersão resultou em um menor consumo de água para a preparação do concreto quando comparado aos demais aditivos (Tabela I)

Os resultados quanto à resistência à tração de concretos preparados com CA14M ou Secar 71 na presença de diferentes aditivos dispersantes, em função do tempo de cura são apresentados na Fig. 1.

Independente do ligante utilizado, os maiores valores de resistência à tração são obtidos na presença do aditivo CS. Além disso, na presença desse aditivo a resistência à tração é aumentada quando os concretos são submetidos à secagem a $110{ }^{\circ} \mathrm{C}$, tornando-se mais significativa a diferença com relação à resistência à tração obtida na presença dos demais aditivos. $\mathrm{O}$ maior desenvolvimento da resistência à tração para os concretos dispersos com CS pode ser relacionado a princípio à eficiente dispersão das partículas proporcionada pela presença desse ligante, o que resulta numa estrutura bem empacotada e, portanto, menos porosa. De fato, as medidas de porosidade aparente para concretos preparados na presença dos diferentes aditivos (Fig. 2) confirmam que concretos preparados com CS apresentam uma porosidade significativamente menor, conseqüência também do menor teor de água consumido.

As curvas de secagem obtidas para os concretos preparados com CA14M ou Secar 71 na presença dos diferentes aditivos em função do tempo de cura são apresentadas na Fig. 3.

Em sistemas de baixa permeabilidade, como concretos refratários ligados com cimento de aluminato de cálcio, a secagem com taxa de aquecimento contínua pode ocorrer em três estágios. O primeiro estágio de aquecimento, evaporação da água livre, consiste na retirada da água fisicamente ligada das camadas mais externas do corpo. Esse estágio ocorre em temperaturas inferiores à do ponto de ebulição do fluido a ser retirado (no caso da água, temperatura inferior a $100{ }^{\circ} \mathrm{C}$ ). Os estágios de secagem são consecutivos e complementares, isto é, cada etapa responde pela eliminação de uma determinada fração do total de água presente no corpo. Com o final da evaporação, inicia-se o segundo estágio de aquecimento, denominado ebulição. Nesta etapa, a remoção da água livre tem como força motriz a geração de vapor a partir do ponto de ebulição. O terceiro estágio se deve a decomposição dos hidratos. Esta etapa é caracterizada pela remoção da água quimicamente combinada ao ligante hidráulico utilizado. Dependendo das fases formadas, essa liberação de água 


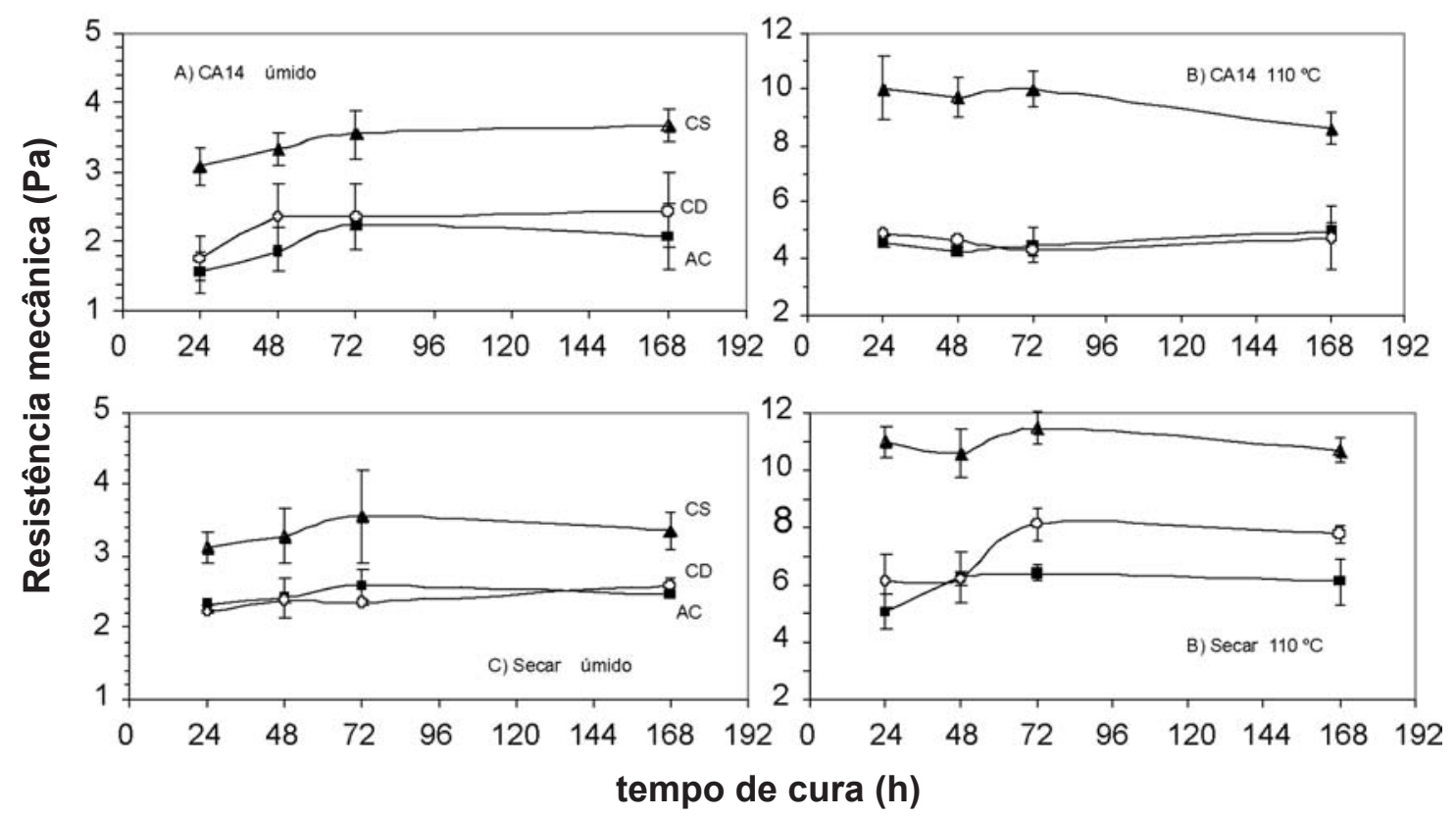

Figura 1: Resistência à tração a úmido ou após secagem a $110^{\circ} \mathrm{C}$, em função do tempo de cura para concretos preparados com CA14M ou Secar 71 na presença de diferentes aditivos dispersantes.

[Figure 1: Traction strength (wet or dried at $110^{\circ} \mathrm{C}$ ) as a function of curing time for castables prepared with CA14M or Secar 71 cement containing different dispersant additives.]

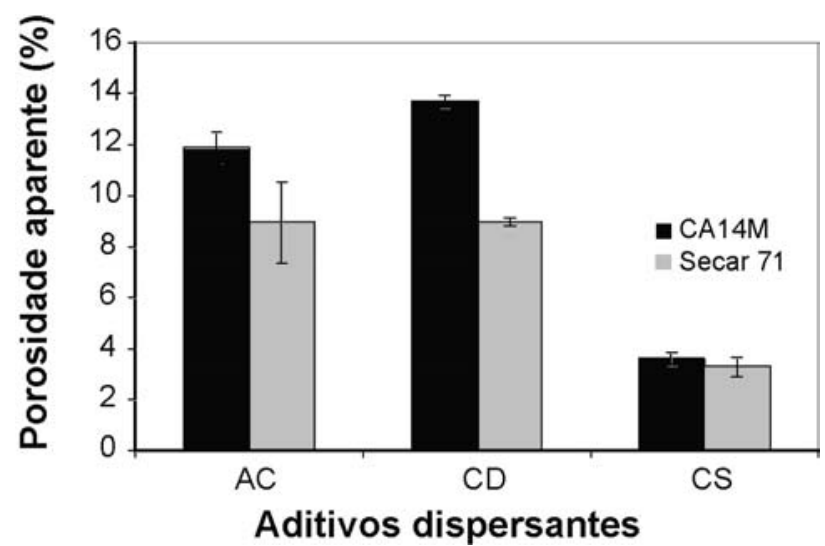

Figura 2: Porosidade aparente para concretos preparados com CA14M ou Secar 71 na presença de diferentes aditivos dispersantes, curados durante $72 \mathrm{~h}$ a $50{ }^{\circ} \mathrm{C}$.

[Figure 2: Apparent porosity for castables prepared with CA14M or Secar 71 in the presence of different additives, cured at $50^{\circ} \mathrm{C}$ for 72 h.]

ocorre em diferentes faixas de temperatura [14, 15].

O processo de hidratação das partículas de cimento em água resulta na precipitação de fases hidratadas de aluminato de cálcio. Em geral, $\mathrm{CAH}_{10}, \mathrm{C}_{2} \mathrm{AH}_{8}, \mathrm{C}_{3} \mathrm{AH}_{6}$ e $\mathrm{AH}_{3}$ são reconhecidos como os principais hidratos de aluminato de cálcio, sendo $\mathrm{C}=\mathrm{CaO}, \mathrm{A}=\mathrm{Al}_{2} \mathrm{O}_{3}$ e $\mathrm{H}=\mathrm{H}_{2} \mathrm{O}$. Quando esses hidratos são aquecidos ocorre a saída da água combinada cujas temperaturas correspondentes podem ser medidas por análise termogravimétrica (ensaios de secagem). $\mathrm{O}$ hidrato
$\mathrm{CAH}_{10}\left(\mathrm{CaO} \cdot \mathrm{Al}_{2} \mathrm{O}_{3} \cdot 10 \mathrm{H}_{2} \mathrm{O}\right)$ e a alumina gel perdem sua água de cristalização por meio de desidratação em baixas temperaturas $\left(100-130{ }^{\circ} \mathrm{C}\right) . \quad \mathrm{O}_{2} \mathrm{C}_{2} \mathrm{AH}_{8} \quad\left(2 \mathrm{CaO} \cdot \mathrm{Al}_{2} \mathrm{O}_{3} \cdot 8 \mathrm{H}_{2} \mathrm{O}\right)$ apresenta decomposição na faixa de temperatura entre $170-195{ }^{\circ} \mathrm{C}$. $\mathrm{O} \mathrm{C}_{3} \mathrm{AH}_{6}\left(3 \mathrm{CaO} \cdot \mathrm{Al}_{2} \mathrm{O}_{3} \cdot 6 \mathrm{H}_{2} \mathrm{O}\right)$ forma durante o processo de desidratação um composto metaestável, $\mathrm{C}_{3} \mathrm{AH}_{1,5}$, após perda de 4,5 moles de água de cristalização $\left(300-360^{\circ} \mathrm{C}\right) . \mathrm{O}$ restante $\left(1,5\right.$ moles) é perdido a aproximadamente $450{ }^{\circ} \mathrm{C}$. Durante a desidratação do $\mathrm{AH}_{3}\left(210-300^{\circ} \mathrm{C}\right)$ uma parte pode se converter em boemita (um monohidrato de alumínio $\mathrm{AH})$. A desidratação do AH ocorre entre 530 e $550^{\circ} \mathrm{C}$ [16]. Entretanto, estes diferentes tipos de hidrato são formados segundo a seqüência apresentada na Fig. 4. O hidrato $\mathrm{CAH}_{10}$ é o produto majoritário quando a cura é realizada em baixas temperaturas $\left(5-10^{\circ} \mathrm{C}\right)$ e com teor suficiente de água. $\mathrm{O}$ hidrato $\mathrm{C}_{2} \mathrm{AH}_{8}$ forma-se em temperaturas entre 22 e $35^{\circ} \mathrm{C}$. Já o $\mathrm{C}_{3} \mathrm{AH}_{6}$ é o hidrato formado majoritariamente em temperaturas acima de $35{ }^{\circ} \mathrm{C}$ ou na presença de teores reduzidos de água. $\mathrm{O}$ hidrato $\mathrm{AH}_{3}\left(\mathrm{Al}_{2} \mathrm{O}_{3} \cdot 3 \mathrm{H}_{2} \mathrm{O}\right)$ forma-se em toda a faixa de temperatura e teores de água, embora o aumento da temperatura e o passar do tempo possa modificar sua estrutura, de amorfa para cristalina. Entre as diferentes fases de aluminato de cálcio hidratado, o $\mathrm{C}_{3} \mathrm{AH}_{6}$ é o mais estável e o $\mathrm{CAH}_{10}$ o menos estável, já para o $\mathrm{AH}_{3}$ a estabilidade aumenta quando este composto passa de amorfo para cristalino [17]. Esta suposição está de acordo com o fato de que, em concretos curados em condições onde as fases $\mathrm{CAH}_{10}$ e $\mathrm{AH}_{3}$ na forma de gel são favorecidas, o tempo ou o aumento da temperatura fazem com que estes materiais passem, gradativamente, a serem constituídos pela fase $\mathrm{C}_{3} \mathrm{AH}_{6}$ e pelo $\mathrm{AH}_{3}$ cristalino. 

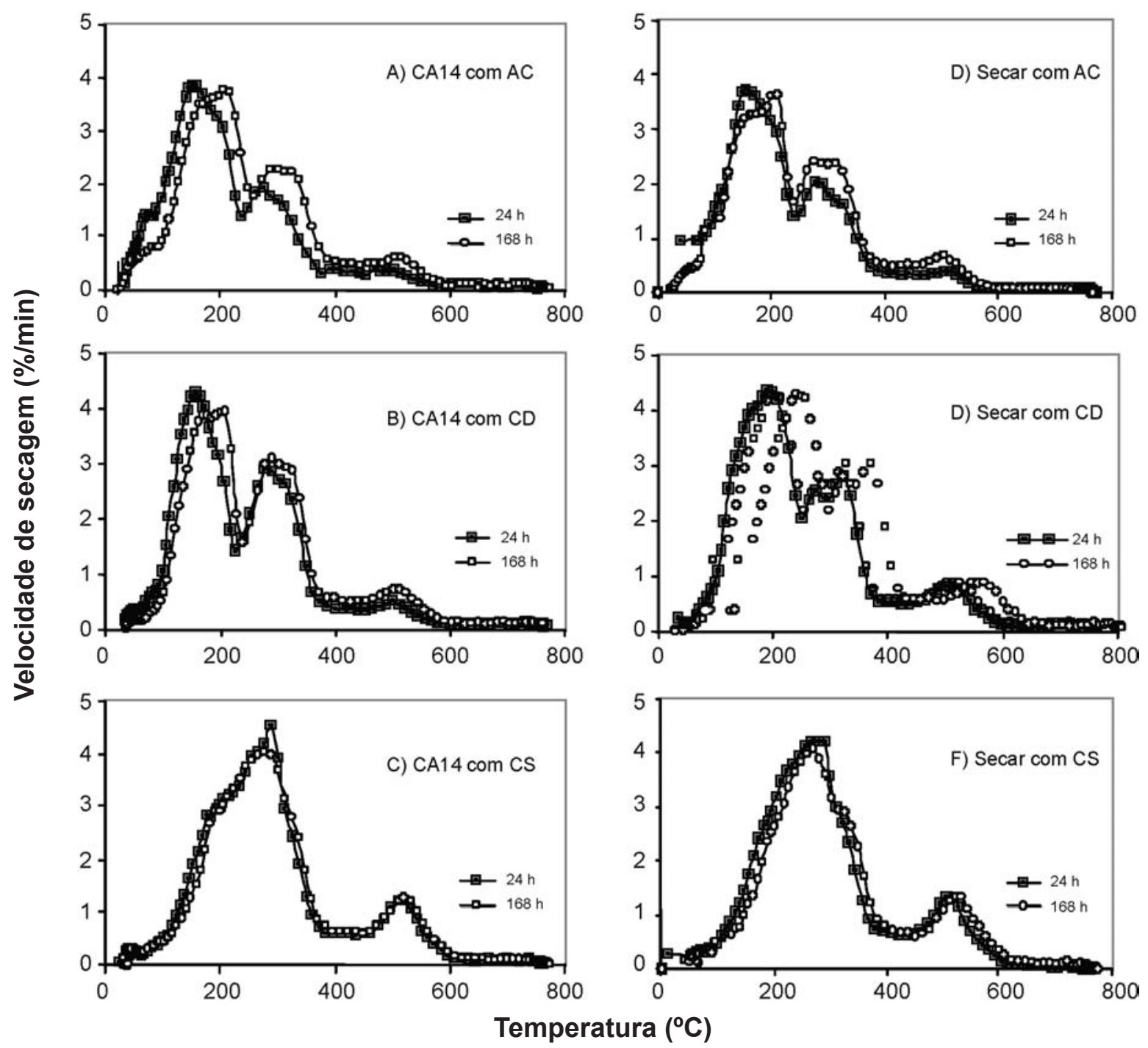

Figura 3: Velocidade de secagem em função da temperatura da amostra para concretos preparados com CA14M ou Secar 71 na presença de diferentes aditivos, para os tempos de cura a $50{ }^{\circ} \mathrm{C}$ de 24 e $168 \mathrm{~h}$.

[Figure 3: Drying rate as a function of the sample temperature for castables prepared with CA14M or Secar 71 containing different additives, for curing time at $50^{\circ} \mathrm{C}$ of 24 and $168 \mathrm{~h}$.]
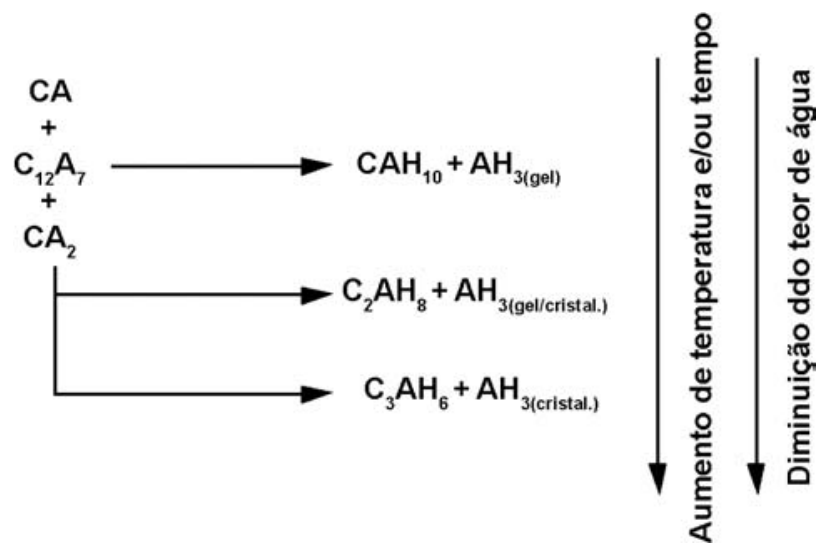

Figura 4: Esquema representando as reações de hidratação mais comuns para CAC.

[Figure 4: General diagram for hydration reaction of CAC.]
Dessa forma, é possível observar por meio dos ensaios de secagem (Figura 3) a existência de alguns picos de desidratação abaixo de $400{ }^{\circ} \mathrm{C}$ os quais não se apresentam bem definidos. Este fato é ainda mais crítico quando utilizado o aditivo CS. A fim de se visualizar melhor a ocorrência dos picos de desidratação estes ensaios foram repetidos utilizando-se amostras secas a $110^{\circ} \mathrm{C}$ (Fig. 5). De fato, pode ser observada mais nitidamente a existência de picos, os quais podem ser relacionados à presença do hidrato $\mathrm{C}_{2} \mathrm{AH}_{8}\left(170-195^{\circ} \mathrm{C}\right), \mathrm{AH}_{3}$ $\left(250^{\circ} \mathrm{C}\right), \mathrm{C}_{3} \mathrm{AH}_{6}\left(350^{\circ} \mathrm{C}\right)$ e $\mathrm{AH}$ por volta de $550{ }^{\circ} \mathrm{C}$.

Tomando como base a ocorrência da formação desses tipos de hidratos, quando comparamos as curvas de secagem apresentadas na Fig. 3 pode-se observar que os tipos de hidratos formados sofreram influência do teor de água disponível, conforme previsto pela Fig. 4. À medida que foi consumido um maior teor de água na preparação do concreto 


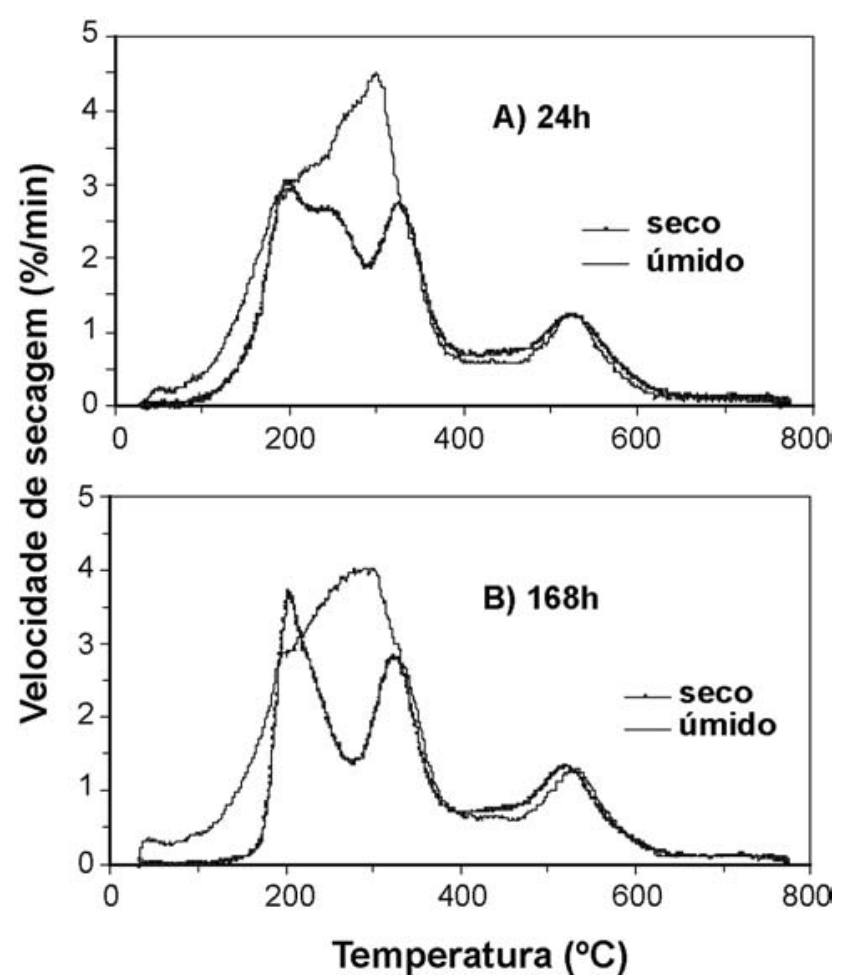

Figura 5: Velocidade de secagem em função da temperatura da amostra para concretos preparados com 6\%-p de CA14M na presença do aditivo $\mathrm{CS}$, úmidos ou secos a $110^{\circ} \mathrm{C}$, para os tempos de cura a $50{ }^{\circ} \mathrm{C}$ de 24 e $168 \mathrm{~h}$.

[Figure 5: Drying rate as a function of the sample temperature for castables prepared with $6 \mathrm{wt} \%$ CA14M and additive CS, wet or dried at $110^{\circ} \mathrm{C}$, for curing time at $50^{\circ} \mathrm{C}$ of 24 and $168 \mathrm{~h}$.]

( $\mathrm{AC}>\mathrm{CD}>\mathrm{CS}$ ) ocorreu a formação preferencial do hidrato $\mathrm{C}_{2} \mathrm{AH}_{8}$, dado ao pico de desidratação característico em torno de $200{ }^{\circ} \mathrm{C}$. Por outro lado, a utilização do aditivo CS como dispersante na preparação dos concretos refratários levou à obtenção de concretos mais fluidos com reduzida porosidade consumindo um menor teor de água quando comparado aos demais aditivos. A presença desse menor teor de água pode justificar a formação preferencial do hidrato $\mathrm{C}_{3} \mathrm{AH}_{6}$ na temperatura de cura utilizada $\left(50^{\circ} \mathrm{C}\right)$. Já quando utilizado $\mathrm{AC}$ além do teor de água disponível para a formação de $\mathrm{C}_{2} \mathrm{AH}_{8}$ ser o maior entre os aditivos testados outro fator pode ter contribuído para a redução quanto a formação de $\mathrm{C}_{3} \mathrm{AH}_{6}$ quando comparado a CD. De acordo com estudos anteriores [18], esse aditivo apresenta um eficiente efeito retardador do mecanismo de hidratação do cimento. Ele seqüestra os íons $\mathrm{Ca}^{2+}$ dificultando a formação de hidratos mais ricos em cálcio como $\mathrm{C}_{3} \mathrm{AH}_{6}$. Isso pode justificar a evolução da altura do pico característico da desidratação do $\mathrm{C}_{3} \mathrm{AH}_{6}$ com o tempo indicando que na presença desse aditivo a formação desse hidrato foi retardada (Fig. 3). Assim, além do menor consumo de água na preparação do concreto uma segunda vantagem com relação ao uso do aditivo CS pode ser atribuída ao fato de que já com $24 \mathrm{~h}$ o material não apresenta nenhuma evolução das fases contribuindo para a redução do tempo de desmoldagem de concretos. Pode-se observar na
Fig. 3 que praticamente toda água adicionada é consumida na formação da fase $\mathrm{C}_{3} \mathrm{AH}_{6}$. Já com ácido cítrico, à medida que se aumenta o tempo de cura de 24 para $168 \mathrm{~h}$, pode ser verificada a formação de uma maior quantidade da fase $\mathrm{C}_{3} \mathrm{AH}_{6}$ reduzindo o teor de água livre observado por meio do pico em torno $100{ }^{\circ} \mathrm{C}$.

A influência do aditivo quanto ao tipo de hidrato a ser formado pode ser melhor visualizada quando comparamos as curvas de secagem para um tempo fixo de cura em função da presença dos diferentes aditivos dispersantes (Fig. 3). Podem-se identificar três regiões bem definidas sendo: 1) região A (abaixo de $200{ }^{\circ} \mathrm{C}$ ) correspondente a presença de água livre e a formação de hidratos com maior teor de água $\left.\left(\mathrm{C}_{2} \mathrm{AH}_{8}\right), 2\right)$ região $\mathrm{B}\left(200-400^{\circ} \mathrm{C}\right)$ correlacionada a formação dos hidratos $\mathrm{C}_{3} \mathrm{AH}_{6}$ e $\mathrm{AH}_{3}$ e 3 ) região $\mathrm{C}\left(500-600{ }^{\circ} \mathrm{C}\right)$ devido a formação do hidrato $\mathrm{AH}$.

Como discutido anteriormente, na presença dos aditivos $\mathrm{AC}$ e $\mathrm{CD}$ a ocorrência de desidratação na região $\mathrm{A}$ é predominante sendo os picos na região $\mathrm{C}$ menos notados principalmente na presença de AC para $24 \mathrm{~h}$ de cura. Por outro lado, quando o aditivo CS é utilizado, ocorre a formação preferencial de hidratos na região B. Entretanto, na presença desse aditivo se destaca a formação de hidratos na região $\mathrm{C}$.

A formação de fases como $\mathrm{AH}_{3}$ é particularmente favorecida pela precipitação do $\mathrm{C}_{3} \mathrm{AH}_{6}$ uma vez que há mais alumina disponível para a formação do hidrato $\mathrm{AH}_{3}$ [19]. Essa fase aparece freqüentemente como um gel e devido a sua alta capacidade de preencher vazios interparticulas pode ser correlacionada ao desenvolvimento de resistência mecânica. A formação preferencial do $\mathrm{C}_{3} \mathrm{AH}_{6}$ quando na presença de $\mathrm{CS}$ pode justificar a maior formação de $\mathrm{AH}_{3}$ e consequentemente o ganho de resistência à tração. A desidratação de uma maior quantidade de $\mathrm{AH}_{3}\left(210-300{ }^{\circ} \mathrm{C}\right)$ pode justificar a superior formação de $\mathrm{AH}$ verificando-se um aumento do pico relativo a região C. Dessa forma, a medida que o aditivo permitiu a formação de um maior teor de $\mathrm{C}_{3} \mathrm{AH}_{6}$ foi observado um maior pico relativo a região $\mathrm{B}\left(\mathrm{C}_{3} \mathrm{AH}_{6}+\mathrm{AH}_{3}\right)$ e consequentemente na região $\mathrm{C}(\mathrm{AH})$

Ensaios realizados para concretos na ausência de ligante utilizando-se como dispersantes os aditivos CS e AC mostraram que não há ocorrência de um pico acima de $500{ }^{\circ} \mathrm{C}$. Isso confirma que tal pico não se deve a hidróxido de alumínio formado a partir das aluminas da matriz (Fig. 6), mas sim de um desbalanceamento entre as concentrações de $\mathrm{CaO}$ e $\mathrm{Al}_{2} \mathrm{O}_{3}$ provenientes do cimento.

Cabe ressaltar que aditivos normalmente empregados na composição de concretos refratários não atuam somente na dispersão das partículas da matriz e ligante, mas o efeito da sua atuação pode influenciar no tipo de hidrato formado. Conseqüentemente a influência dos aditivos foi verificada na resistência à tração e no comportamento de secagem dos concretos, se mantendo até mesmo em propriedades em alta temperatura, cujo estudo esta sendo realizado.

A fim de entender melhor a influência dos aditivos, os ensaios de secagem também foram realizados para composições na ausência destes. Pode ser observado na Fig. 7 


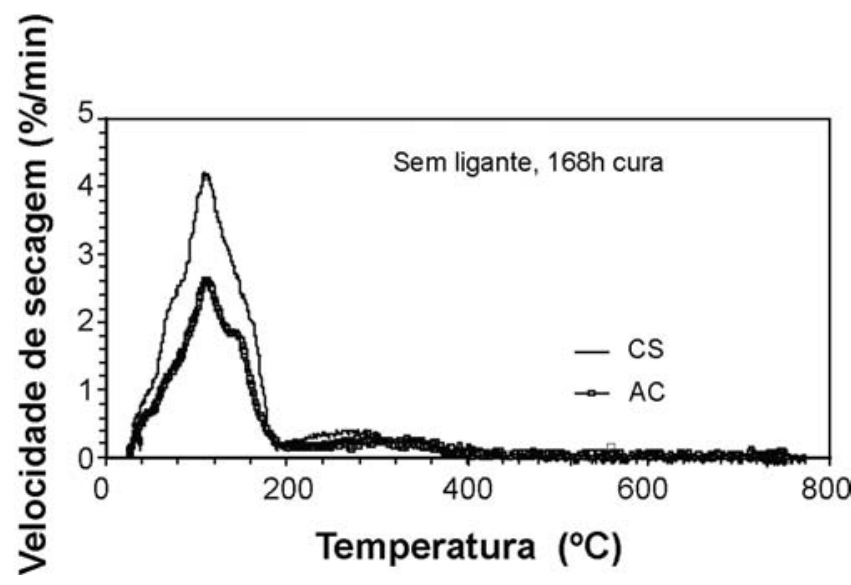

Figura 6: Velocidade de secagem em função da temperatura da amostra para concretos preparados na ausência de ligante (4,5\%$\mathrm{p}$ de água) utilizando-se como dispersante os aditivos CS e AC, curados durante $168 \mathrm{~h}$.

[Figure 6: Drying rate as a function of the sample temperature for castables prepared without binder but containing $C S$ and $A C$ additives (curing at $50^{\circ} \mathrm{C}$ for $168 \mathrm{~h}$ ). ]

que o teor de água livre a ser eliminada durante o aquecimento é significativamente aumentado (pico próximo $100{ }^{\circ} \mathrm{C}$ ). Isso mostra que parte da água adicionada na preparação do concreto não está sendo utilizada na formação de hidratos. $\mathrm{Na}$ ausência de aditivo a dispersão do ligante fica prejudicada fazendo com que menos partículas (área superficial) sejam expostas a hidratação reduzindo o consumo de água livre para a formação de hidratos. Já quanto melhor for a dispersão das partículas do ligante maior a hidratação e o consumo de água para a formação das fases hidratadas restando menos água livre a ser eliminada durante a secagem. Isso reduz os riscos de explosão do concreto durante esta etapa do processamento. Também é observado um pico bem melhor definido relativo a formação de $\mathrm{C}_{3} \mathrm{AH}_{6}$ quando comparado ao mesmo pico na presença de aditivos. Essa diferença parece estar associada ao decréscimo na formação do hidrato $\mathrm{AH}_{3}$ e consequentemente de $\mathrm{AH}$. Portanto, somente a formação preferencial de $\mathrm{C}_{3} \mathrm{AH}_{6}$ não garante a formação de $\mathrm{AH}_{3}$.

Os corpos moldados na ausência de aditivos apresentaram muitos defeitos, resultando numa estrutura muito mais porosa quando comparada à estrutura de corpos obtidos a partir de concretos bem dispersos. Essa característica estrutural parece influenciar na formação de hidratos de alumina sendo que quanto mais densa a estrutura mais propicia a formação de $\mathrm{AH}_{3}$, como ocorre na presença de CS. Um outro fator que pode propiciar a formação de $\mathrm{AH}_{3}$ é o aumento de temperatura. Isso poderia justificar o significativo aumento de resistência à tração verificado para os corpos quando na presença de CS secos a 110 ${ }^{\circ} \mathrm{C}$ quando comparado aos corpos úmidos.

Comparando-se as curvas de secagem obtidas na presença dos distintos ligantes estudados (CA14M e Secar 71) não é observada diferença quanto a formação de fases quando na presença de CS. Por outro lado, na presença de $\mathrm{CD}$ a formação da fase $\mathrm{AH}$ se destaca quando

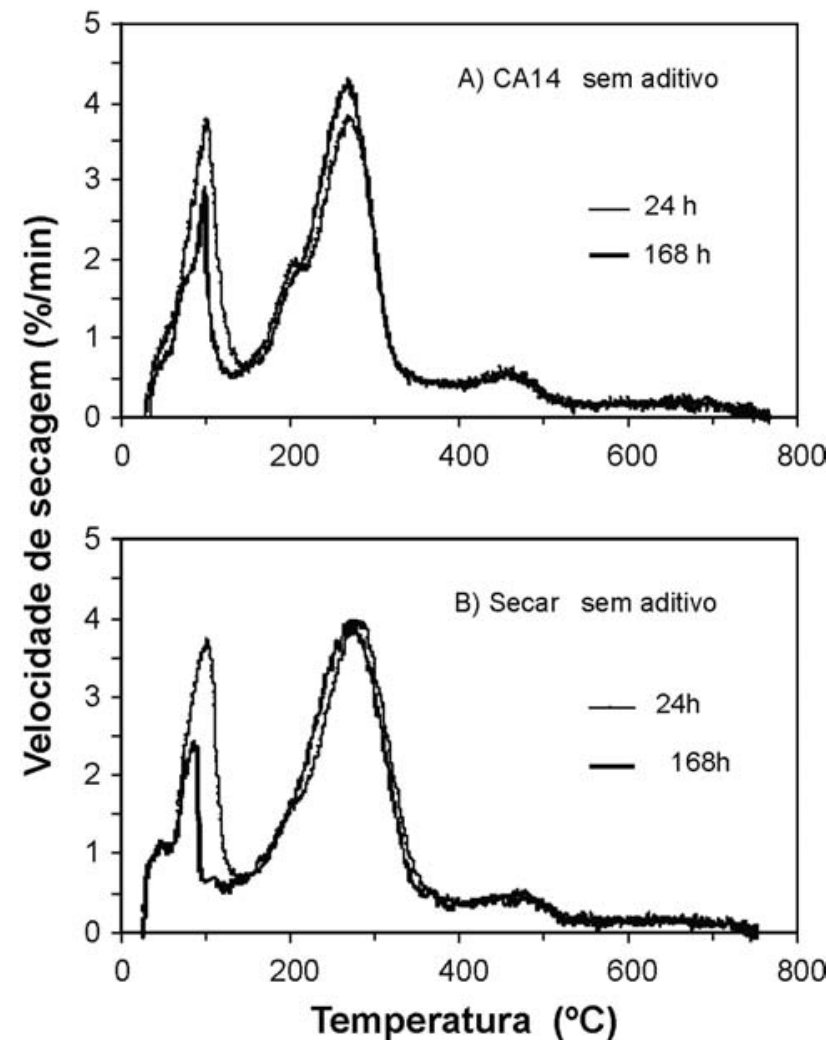

Figura 7: Velocidade de secagem em função da temperatura da amostra para concretos preparados com CA14M ou Secar 71 sem aditivos, para os tempos de cura a $50{ }^{\circ} \mathrm{C}$ de 24 e $168 \mathrm{~h}$.

[Figure 7: Drying rate as a function of the sample temperature for castables prepared with CA14M or Secar 71 without additives, for curing at $50^{\circ} \mathrm{C}$ for 24 and $\left.168 \mathrm{~h}.\right]$

o ligante usado é o Secar 71 (Fig. 3). De fato, quando se comparam os resultados de resistência à tração obtidos na presença dos distintos ligantes, após secagem a $110{ }^{\circ} \mathrm{C}$ (Fig. 1), ocorreu uma maior diferença na presença de CD. Isso comprova que o favorecimento quanto a formação de $\mathrm{AH}_{3}$ e conseqüentemente $\mathrm{AH}$ na presença de Secar 71-CD contribuiu para o aumento da resistência à tração. Entretanto, os resultados mostram que na presença de CS a resistência à tração obtida com o sistema Secar 71-CD é superada independente do ligante usado. Dessa forma, a composição formada na presença do ligante Secar 71 e o aditivo CS pode ser apontada como a mais eficiente para a preparação de concretos, entre as diferentes composições avaliadas. Podese aliar uma eficiente dispersão do concreto e elevada fluidez com aumento de resistência à tração. Entretanto, o fato de gerar uma estrutura mais densa pode dificultar a secagem do material acarretando em prejuízos como a explosão do corpo dependendo da taxa de aquecimento usada.

\section{CONCLUSÕES}

Os aditivos normalmente empregados na composição de concretos refratários não atuam somente na dispersão das 
partículas da matriz e ligante, mas o efeito da sua atuação pode influenciar no tipo de hidrato formado.

$\mathrm{O}$ aditivo CS se destaca como um eficiente dispersante, promovendo a redução no consumo de água. Isso acarreta na formação preferencial dos hidratos $\mathrm{C}_{3} \mathrm{AH}_{6}$ disponibilizando mais alumina para a formação de $\mathrm{AH}_{3}$. Esses tipos de hidratos contribuem para aumentar a resistência à tração do material.

Por outro lado, o aditivo AC desfavorece a formação do hidrato $\mathrm{C}_{3} \mathrm{AH}_{6}$ uma vez que atua por meio do consumo de íons cálcio. Também a presença de um maior teor de água nos concretos preparados com AC contribui para a formação do hidrato $\mathrm{C}_{2} \mathrm{AH}_{8}$.

A formação do hidrato $\mathrm{AH}_{3}$ é ainda mais favorecida quando o ligante utilizado é o Secar 71, resultando em superior resistência à tração quando comparado ao uso de CA14M.

\section{AGRADECIMENTOS}

A Almatis e Kerneos pelo fornecimento das matériasprimas e a FAPESP e CNPq pelo suporte financeiro.

\section{REFERÊNCIAS}

[1] F. T. Ramal Jr., R. Salomão, V. C. Pandolfelli, "Comportamento de secagem e explosão de concretos refratários com diferentes teores de água”, Cerâmica 50, 315 (2004) 197-201.

[2] M. D. M. Innocentini, J. Yamamoto, C. Ribeiro, R. G. Pileggi, A. C. Rizzi Jr., L. R. M. Bittencourt, R. P. Rettore, V. C. Pandolfelli, "Efeito da distribuição granulométrica na secagem de concretos refratários", Cerâmica 47, 304 (2001) 212-218.

[3] C. Parr, C. Wohrmeyer, B. Valdelievre, A. Namba, "Effect of formulation parameters upon the strength development of calcium aluminate cement containing castables", J. Techn. Assoc. Refract. 23, 4 (2003) 231-238.

[4] H. Fryda, K. Scrivener, T. Bier, B. Espinosa, "Relation between setting properties of low cement castables and interactions within the binder system (CAC-fillersadmixtures-water)", in Proc. Unified Int. Conf. Refract. UNITECR 95, Kyoto (1995) 1315-1323.

[5] N. Bunt, C. Revais, M. Vialle, "Additives in calcium aluminate cement containing castables" in Proc. Unified Int. Conf. Refract. - UNITECR 97, New Orleans (1997) 13471354.

[6] J. S. Reed, "Drying”, Ceramic Age 87, 7 (1971) 81.

[7] G. W. Scherer, "Theory of drying”, J. Am. Ceram. Soc. 73, 1 (1990) 3-14.

[8] I. R. Oliveira, A. R. Studart, R. G. Pileggi, V. C. Pandolfelli, "Dispersão e empacotamento de partículas - princípios e aplicações em processamento cerâmico", Fazendo Arte Editorial (2000) 195 p.

[9] R. G. Pileggi, "Ferramentas para o estudo e desenvolvimento de concretos refratários", Tese de doutorado, UFSCar. S. Carlos, SP (2001) 187p.

[10] I. R. Oliveira, V. C. Pandolfelli, "Reologia de concretos refratários na presença de diferentes tipos de aditivo e ligante hidráulico", Cerâmica, Cerâmica 53, 327 (2007).

[11] R. G. Pileggi, V. C. Pandolfelli, A. E. Paiva, J. Gallo, "Novel rheometer for refractory castables", Am. Ceram. Soc. Bull. 79, 1 (2000) 54-58.

[12] R. G. Pileggi, A. R. Studart, V. C. Pandolfelli, "How mixing affects the rheology of refractory castables. Part I", Am. Ceram. Soc. Bull. 80, 6 (2001) 27-31.

[13] R. G. Pileggi, A. R. Studart, V. C. Pandolfelli, "How mixing affects the rheology of refractory castables. Part II", Am. Ceram. Soc. Bull. 80, 7 (2001) 38-42.

[14] M. D. M. Innocentini, F. Cardoso, M. Akiyoshi, V. C. Pandolfelli, "Drying stages during the heat-up of highalumina, ultra low cement refractory castables", J. Am. Ceram. Soc. 86, 7 (2003) 1146-1148.

[15] M. D. M. Innocentini, F. Cardoso, M. Miranda, V. C. Pandolfelli, "Vaporization process and pressure buildup during the dewatering of dense refractory castables", J. Am. Ceram. Soc. 86, 9 (2003) 1500-1503.

[16] T. D. Robson, "Aluminous Cement in refractory castables", in The Chemistry of cements, Vol. 2, Academic Press (1964).

[17] K. M. Parker, J. H. Sharp, "Refractory calcium aluminate cements”, Trans. J. Brit. Ceram. Soc. 81 (1982) 35-42.

[18] I. R. Oliveira, V. C. Pandolfelli, "Hidratação de ligantes na presença de matriz e aditivos", Cerâmica 53, 327 (2007) [19] R. Turriziani, "The calcium aluminate hydrates and related compounds", in The Chemistry of Cements, Vol. 1, Ed. H. F. W. Taylor, Academic Press (1964) 233-286.

(Rec. 19/04/2007, Rev. 12/06/2007, Ac. 15/06/2007) 